\title{
ANÁLISE MICROETNOGRÁFICA DA (CO)PRODUÇÃO DA TRANSEXUALIDADE EM UM ATENDIMENTO CLÍNICO
}

\author{
ANÁLISIS MICROETNOGRÁFICO DE LA (CO)PRODUCCIÓN DE LA \\ TRANSEXUALIDAD EN UN SERVICIO CLÍNICO
MICROETHNOGRAPHIC ANALYSIS OF THE (CO)PRODUCTION OF TRANSSEXUALITY IN A CLINICAL APPOINTMENT

\section{Marcela Alberti ${ }^{1}$, Willian Maciel Krüger ${ }^{1}$, Alexandre do Nascimento Almeida ${ }^{1} \mathrm{e}$ Lucia Marques Stenzel ${ }^{1}$}

${ }^{1}$ Universidade Federal de Ciências da Saúde de Porto Alegre, Porto Alegre/RS, Brasil

\begin{abstract}
RESUMO: O objetivo deste artigo é descrever e analisar práticas interacionais que emergem no contex to de psicoterapia em um núcleo clínico especializado em gênero e sexualidade. O material de análise consiste em um atendimento entre um psiquiatra e uma mulher transexual, o qual foi escolhido a partir de um corpus de cinco atendimentos gravados pelo núcleo. Realizamos uma análise microetnográfica ancorada na linha teórico-metodológica da Análise da Conversa. Observamos duas práticas interacionais que emergem de maneira recorrente: formulação e prestação de contas. Tais práticas estão a serviço da realização de uma tarefa institucional: a (co)produção de um laudo psiquiátrico atestando, a partir de uma matriz nosológica, a transexualidade da cliente. Nossa análise aponta que o DSM-5 e a CID-11 são instrumentos que, no atendimento clínico a pessoas transexuais, limitam a autonomia de cliente e terapeuta e consolidam dispositivos que mantêm a cisnormatividade como regra.

PALAVRAS-CHAVE: Transexualidade; Gênero; Despatologização; Análise da conversa; Psicoterapia.
\end{abstract}

RESUMEN: El objetivo de este artículo es describir y analizar las prácticas interaccionales que surgen en el contexto de psicoterapia en un centro clínico especializado en género y sexualidad. El material de análisis consiste en un servicio entre un psiquiatra y una mujer transexual, elegido a partir de un corpus de cinco consultas grabadas por el centro. Realizamos un análisis microetnográfico anclado en la línea teórico-metodológica del Análisis de Conversación. Observamos dos prácticas interaccionales que surgen de forma recurrente: formulación y rendición de cuentas. Tales prácticas están al servicio de la realización de una tarea institucional: la (co)producción de un informe psiquiátrico que atestigüe, desde una matriz nosológica, la transexualidad de la cliente. Nuestro análisis muestra que el DSM-5 y la ICD-11 son instrumentos que, en lo servicio clínico a las personas transexuales, limitan la autonomía de la cliente y el terapeuta y consolidan dispositivos que mantienen la cisnormatividad como regla.

PALABRAS CLAVE: Transexualidad; Género; Despatologización; Análisis de la conversación; Psicoterapia.

ABSTRACT: This article aims to describe and analyze interactive practices that emerge in the context of psychotherapy in a clinical center specialized in gender and sexuality. The material under analysis consists of an appointment between a psychiatrist and a transsexual woman, which was select from a research corpus of five appointments videorecorded by the center. We conducted a microethnographic analysis based on the Conversation Analysis theoretical and methodological framework. We observed two interactional practices that emerge in a recurrent manner: formulation and accountability. Such practices are in service of the accomplishment of an institutional task: the (co)production of a psychiatric report that certifies the client's transsexuality from a nosological matrix. Our analysis points out that DSM-5 and ICD-11 are devices that, in the clinical care for transsexual people, limit the autonomy of both therapist and client, as well as consolidate apparatuses that maintain cisnormativity as a rule.

KEYWORDS: Transsexuality; Gender; Depathologization; Conversation analysis; Psychotherapy. 


\section{Introdução}

A alteração de nome e gênero no assento de registro civil de pessoas transexuais, bem como as cirurgias de modificação corporal, têm sido alvo de debates tanto no âmbito jurídico quanto no campo da saúde. Até primeiro de março de 2018, pessoas transexuais que desejassem alterar seu nome e gênero no assento de registro civil precisavam de um laudo psiquiátrico que as diagnosticasse como transexuais legítimas/os, isto é, que preenchessem critérios definidos como fundamentais para o diagnóstico de Transtorno da Identidade Sexual (World Health Organization [WHO], 1992). Desde então, tendo a decisão do Supremo Tribunal Federal (STF) sido reiterada a partir de provimento disposto pelo Conselho Nacional de Justiça (2018), laudo médico e parecer psicológico que atestem a transexualidade tornaram-se documentos facultativos para esse tipo de processo. Usamos o termo "transexuais legítimas/os" (Borba, 2014; Santos, 2011) para referir um modelo metapragmático de identidade que se origina da "construção da norma da transexualidade a partir de critérios científicos e clínicos e esquadrinhamentos de corpos e subjetividades" (Santos, 2011, p. 127), configurando-se tanto pela construção do próprio diagnóstico psiquiátrico quanto pelo desenvolvimento de uma condução terapêutica.

Embora a não obrigatoriedade represente um avanço para os direitos de travestis e transexuais no Brasil, se para a alteração do registro civil não é mais necessário o crivo de uma/um psiquiatra, o acesso a outros processos, como a ingestão de hormônios e cirurgias de modificação corporal, ainda requer laudos psiquiátricos/psicológicos que declarem que a pessoa é reconhecida como uma/um transexual legítima/o (Almeida \& Murta, 2013). Tal reconhecimento, que está nas mãos de ditas/os experts, envolve o enquadramento em critérios impostos no Manual Diagnóstico e Estatístico de Transtornos Mentais (DSM5) e na Classificação Estatística Internacional de Doenças e Problemas Relacionados à Saúde (CID 11). São esses documentos que comumente guiam a prática de profissionais da saúde mental que atendem pessoas transexuais em busca de um "aval” para vivenciar a transexualidade da maneira que desejam.

Ainda que o diagnóstico de Disforia de Gênero esteja descrito em um manual que se propõe a classificar transtornos mentais (American Psychiatric Association [APA], 2013), no Brasil, o próprio Conselho Federal de Psicologia (CFP) não reconhece as travestilidades e transexualidades como condições psicopatológicas, desvio ou inadequação, mas sim como possibilidades de existência humana, dando ênfase à autodeterminação como um processo que garante a autonomia de cada sujeito para determinar sua identidade de gênero (Conselho Federal de Psicologia [CFP], 2018). Nesse sentido, a atuação de profissionais da área psi (psiquiatria, psicologia e psicanálise) que são sensíveis a questões de gênero e sexualidade torna-se um desafio diante de disputas que, por um lado, impõem uma psiquiatrização e pretensa universalização das vivências trans (pessoas travestis, transexuais e transgêneras, cf. Carvalho \& Carrara, 2013) e, por outro, combatem a transfiguração de uma categoria cultural (gênero) em uma categoria diagnóstica (Bento, 2016).

Não obstante a publicação do DSM-5 tenha trazido mudanças importantes, principalmente no que se refere à retirada do termo "transtorno" e sua substituição por "disforia", a transexualidade segue enquadrada como categoria diagnóstica, desta vez nomeada como "Disforia de Gênero" (APA, 2013). Outra mudança importante se refere à retirada da transexualidade da lista de doenças mentais na CID 11; a transexualidade, entretanto, ainda aparece nesse documento, mas agora nomeada como incongruência de 
gênero e dentro da categoria de condições relativas à saúde sexual. Dessa forma, mesmo com as mudanças realizadas (recentes e que, portanto, ainda encontram pouco respaldo institucional e na prática clínica em si), o DSM e a CID são, ainda hoje, instrumentos de patologização das identidades trans e de negação da autonomia de pessoas transexuais, pois a catalogação da transexualidade como categoria diagnóstica deveria ser compreendida a partir da construção do dispositivo da transexualidade. A construção desse dispositivo se dá em um contexto no qual o corpo individual e social é medicalizado, passando por um processo no qual as experiências que fogem à lógica cisgênera (i.e., o pensamento hegemônico da linearidade entre gênero designado no nascimento e a identidade de gênero como norma, cf. Gomes de Jesus, 2012) e à matriz heterossexual (Butler, 2015) tornam-se do âmbito médico e, principalmente, psiquiátrico, sendo acompanhadas pelas abordagens da psicologia e psicanálise (Santos, 2011). Dessa maneira, entendemos que tais processos impõem restrições às possibilidades de vida às pessoas situadas nas diversidades corporais e de identidades de gênero (Vergueiro, 2015).

Diante disso, a discussão em torno da (des)patologização das identidades trans é primordial para o campo da Psicologia, já que o próprio movimento social LGBT (lésbicas, gays, bissexuais, travestis, transexuais e transgêneros) questiona a forma como o campo de saber das ciências psi delimita certo olhar acerca dos corpos e identidades de gênero (Bagagli, 2016). Ademais, como profissionais da Psicologia, ocupamos o lugar de gatekeepers no acesso a terapias hormonais e outras modificações corporais para a reafirmação da identidade de gênero. O termo "gatekeepers" se refere às práticas médicas de controle sobre os corpos e identidades trans, que determinam o acesso a cuidados médicos, laudo, terapias hormonais e/ou cirurgias de reafirmação de gênero, práticas que controlam a forma como as pessoas trans narram suas identidades, tornando as/os profissionais das ciências psi as/ os detentoras/es do poder de decisão sobre uma pessoa ser ou não ser uma/um "transexual verdadeira/o" (Speer \& Parsons, 2006). Desse modo, torna-se pertinente olhar como se dão as interações em nível micro, isto é, dentro do próprio setting terapêutico, pois é justamente nesse contexto que o sujeito poderá ser (ou não) reconhecido, por uma/um profissional da psicologia ou psiquiatria, como uma/um transexual legítima/o.

Neste artigo, analisamos um atendimento realizado no âmbito de um núcleo especializado na temática da diversidade sexual e de gênero em que uma mulher transexual busca a obtenção de um laudo psiquiátrico para alteração de seu registro civil. Utilizaremos aqui o termo "mulher transexual" para referir pessoas transexuais que se reconhecem na identidade de gênero mulher, embora seu gênero designado no nascimento tenha sido o masculino. Dessa maneira, estamos dando ênfase à identidade de gênero, e não ao gênero designado a partir de marcadores biológicos.

Para realizar uma análise microetnográfica, utilizamos a linha teórico-metodológica da Análise da Conversa (AC) de base etnometodológica. A AC volta-se para o estudo da ação social humana situada no espaço e no decorrer do tempo real, realizando uma abordagem fortemente empírica ao estudo da ação social, evitando qualquer teorização prematura (Loder \& Jung, 2008). Portanto, os estudos a partir da AC centram-se em dados de ocorrência natural, fundamentando-se essencialmente em processos de observação, registro, transcrição e posterior análise de dados empíricos (ten Have, 2012). Desse modo, a AC torna-se um arcabouço teórico-metodológico valioso para analisarmos interações no âmbito do setting terapêutico, pois a concepção de psicoterapia que trazemos aqui é de um evento interacional, de caráter institucional, fruto do encontro entre terapeuta(s) e 
cliente(s) (Peräkylä, Antaki, Vehviläinen, \& Lauder, 2008). Para analistas da conversa, as ferramentas de interação que são tratadas como específicas da psicoterapia são, de fato, ancoradas em ferramentas genéricas da interação social. A AC se constitui, portanto, como uma alternativa para apresentar e discutir dados de encontros psicoterapêuticos, desdobrando, de maneira minuciosa, padrões e práticas interacionais através dos quais a psicoterapia é feita (Peräkylä et al., 2008).

Cabe ressaltar que, ao analisarmos a interação dentro do setting terapêutico, não discutimos as intervenções terapêuticas para avaliá-las como efetivas ou adequadas terapeuticamente conforme a abordagem que se propõem a seguir. No entanto, nosso objetivo é descrever e analisar, sob um ponto de vista microetnográfico, as práticas interacionais que emergem no atendimento. A análise centra-se nos recursos interacionais utilizados por terapeuta e cliente para a construção de uma consulta pautada em princípios que questionam a visão tradicional que coloca pessoas que não seguem a lógica cisheterossexista como transtornadas mentais. Nos deparamos, entretanto, com as amarras que surgem em virtude da própria necessidade de elaboração de um laudo que siga o modelo canônico de dispositivos como o DSM. É válido apontarmos que o uso de cliente (em substituição a paciente) menciona o caráter bidirecional (e contratual) da interação terapêutica como um serviço também requisitado pela/o usuário/a.

\section{Cenário teórico-metodológico}

\section{O cenário de pesquisa}

Os dados analisados aqui fazem parte de um corpus de cinco consultas, fruto de projeto aprovado pelo Comitê de Ética (CEP/UFCSPA, Parecer n. 2.447.440), com clientes que buscaram um núcleo de atendimento especializado em gênero e sexualidade. As consultas gravadas têm, em média, uma hora de duração, totalizando cinco horas de interação. O núcleo se insere no contexto de uma clínica privada, cujo corpo clínico conta com profissionais da área da saúde mental: psicólogas/os (majoritariamente) e psiquiatras. O núcleo tem encontros semanais e realiza, além de atendimentos em sala de espelhos, consultoria, supervisão e seminários teóricos. Os dados gerados para este estudo consistem em primeiras consultas realizadas em sala de espelhos, isto é, embora inseridas em um setting terapêutico, não se tratam de atendimentos que visem a um tratamento psicoterápico contínuo. Embora as pessoas possam obter encaminhamentos para tratamento no próprio núcleo ou fora dele, o objetivo das consultas iniciais é a compreensão da demanda de quem busca ajuda. Nosso trabalho de geração de dados se deu em um período de vinte meses, quando a primeira autora realizou inserções etnográficas em campo, participando dos encontros semanais do núcleo entre abril de 2017 e dezembro de 2018. Os dados gerados são de ocorrência natural, isto é, não são motivados exclusivamente para fins desta pesquisa, pois os atendimentos e mesmo as gravações já aconteciam independentemente deste estudo.

Das cinco consultas cedidas pelo núcleo para o nosso projeto, optamos por centrar a análise aqui em uma devido ao caráter singular e potencial para a compreensão de como ocorrem o reconhecimento e a legitimação da transexualidade na interação. 
Embora desde primeiro de março de 2018 não seja mais necessário laudo para alteração de nome e gênero no assento de registro civil, o atendimento referido aconteceu no final do ano de 2017, quando ainda eram necessários não apenas o laudo psiquiátrico, mas também procedimentos cirúrgicos de reafirmação de gênero.

Todas/os as/os participantes assinaram um termo de consentimento livre e esclarecido (TCLE) permitindo o uso dos dados (gravações dos atendimentos) para fins de pesquisa. Aos dados gerados foi dado tratamento ético através do uso de pseudônimos para proteger o anonimato das/dos participantes. Foram utilizados procedimentos microetnográficos de análise dos dados (Garcez, Bulla, \& Loder, 2014), incluindo a transcrição com a utilização das convenções adotadas no sistema Jefferson (Hepburn \& Bolden, 2013) (ver Anexo 1).

\section{Análise da Conversa}

A linha teórico-metodológica que utilizamos para análise dos dados é a Análise da Conversa (AC), originada na Etnometodologia, a qual contesta os métodos tradicionalmente utilizados pela sociologia para investigar a organização da sociedade. A partir de uma perspectiva êmica de análise de dados, podemos nos valer do olhar das/os próprias/os participantes do estudo para compreender como ocorre a interação e o que está sendo realizado pelas pessoas envolvidas no evento sob análise (Silva, Andrade, \& Ostermann, 2009). Ademais, os estudos a partir da AC centram-se em dados de ocorrência natural, isto é, eventos e interações que aconteceriam independentemente da ação da/do pesquisadora/ or (Loder \& Jung, 2008). À luz da AC, a interação é analisada a partir do sistema da tomada de turnos de fala - unidades como sentenças, orações, palavras isoladas, locuções frasais etc. Dessa maneira, a noção de sequencialidade da interação é um aspecto central da ação social, pois nos remete à ideia de que uma/um interlocutora/or, ao tomar seu turno, não o faz de forma desordenada, mas leva em conta uma ação produzida em turno anterior.

É pertinente apontarmos que a AC não se interessa apenas pela conversa cotidiana, mas tem como foco de análise, também, o que chamamos de fala-em-interação institucional, a qual se dá sempre que ao menos uma/um das/dos interagentes constrói seu turno de fala estabelecendo ou mantendo a "institucionalidade" da interação. Nesse sentido, a falaem-interação institucional é perpassada por uma assimetria maior no que diz respeito a direitos e deveres de cada interlocutora/or, se comparada à conversa cotidiana. Direitos e deveres, aqui, referem-se a quem tem o direito de perguntar e quem deve responder (Sell \& Ostermann, 2015). Portanto, é a/o representante da instituição (no caso deste estudo, o psiquiatra) quem tem o poder de controlar o fluxo da interação, delimitando tópicos, controlando a tomada e extensão dos turnos, requisitando narrativas etc.

Embora a fala-em-interação institucional possa acontecer em qualquer lugar, há eventos em que se torna mais evidente, como é o caso de sala de aula, consultas médicas, atendimentos psicológicos, entre outros. Tais eventos, embora distintos, têm algo em comum: em todos os casos a interação está a serviço da realização de uma tarefa bem definida. No caso do atendimento que analisamos para este estudo, como veremos a seguir, a principal tarefa desenvolvida pela cliente e pelo psiquiatra é a (co)construção de um laudo. Entretanto, a partir dos dados, iremos perceber que outros objetivos próprios do atendimento psicológico emergem na interação, como a construção da demanda da cliente e a avaliação da necessidade ou não de seguir em psicoterapia. 
O uso da AC para analisar atendimentos psicoterapêuticos já tem um caminho traçado: a aproximação entre AC e Psicologia, de maneira mais ampla, também traz consigo uma tradição (ten Have, 2012). O conhecimento já estabelecido sobre algumas práticas psicoterapêuticas é muitas vezes generalista, pois acaba por não analisar os detalhes de tais práticas em sua ocorrência natural e por não reconhecer ou discutir ferramentas interacionais que fazem parte da psicoterapia. O desafio para a AC, para a Psicologia e, de maneira mais específica, para sessões de psicoterapia é explicar essas práticas em maiores detalhes, apontando e descrevendo recursos discursivos de interação - maneiras particulares de realizar questionamentos, escutar ou comentar os turnos de fala das/ dos clientes - que fazem parte da psicoterapia, mas que as teorias psicoterapêuticas não reconhecem ou discutem (Peräkylä et al., 2008), talvez pela escassez de pesquisas focadas em dados de ocorrência natural.

\section{Análise dos resultados}

O atendimento investigado para este estudo consiste em uma consulta na qual é realizada uma entrevista clínica a partir da interação entre um especialista qualificado e uma cliente que buscou o serviço. Observamos, no atendimento analisado, características que são próprias da entrevista clínica, consistindo em um conjunto de técnicas de investigação que objetivam descrever e avaliar aspectos pessoais, relacionais e sistêmicos da participante que busca atendimento, tendo em vista realizar encaminhamentos e propor intervenções (Tavares, 2007). Ademais, o atendimento caracteriza-se, também, pela realização de uma tarefa institucional: a (co)construção de um laudo psiquiátrico que permita à cliente a alteração de seu registro civil. A escolha dos excertos apresentados nesta sessão se deu a partir de um trabalho analítico no qual toda a entrevista foi transcrita de acordo com as convenções adotadas no sistema Jefferson (Anexo 1) e, em seguida, segmentada para enfatizar as práticas interacionais realizadas pelo terapeuta. Dessa maneira, salientamos duas práticas interacionais que se apresentaram de maneira recorrente nos dados gerados: a formulação e a prestação de contas. Enquanto a primeira é reconhecida como prática comumentemente realizada em settings terapêuticos (Peräkylä et al., 2008), a prestação de contas é uma prática que, embora amplamente estudada no âmbito da AC e onipresente nos eventos de fala, não é habitualmente pensada no âmbito da psicoterapia.

\section{Formulação}

O excerto 1 (Figura 1) ocorre ainda no início da consulta, quando Ademir solicita a Rafaela que conte como foi seu processo de reconhecer-se em uma identidade de gênero feminina. 


\section{Figura 1: Excerto 1}

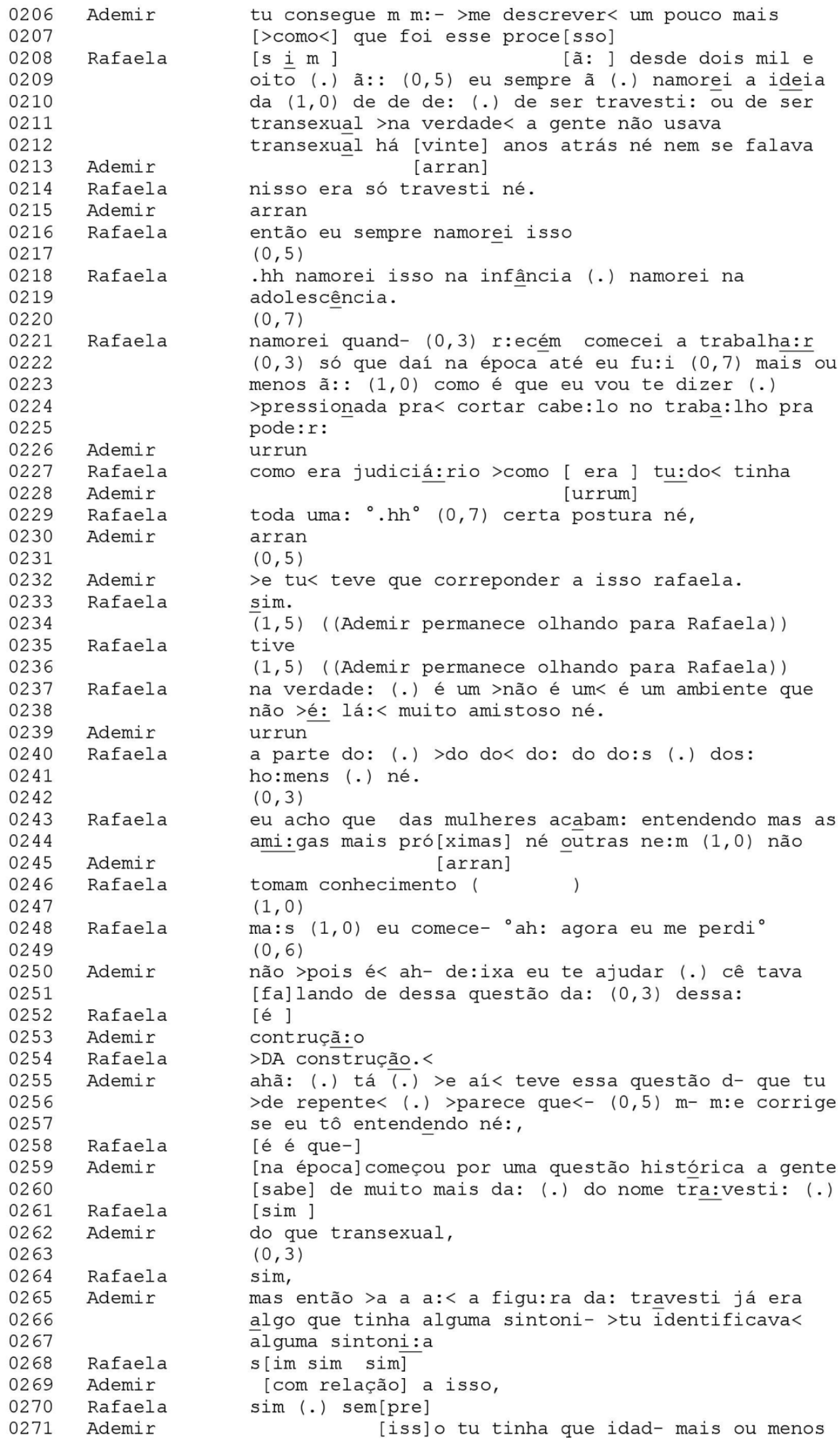


Rafaela inicia a produção da narrativa solicitada por Ademir (linha 209) e busca situálo no sentido temporal de sua construção identitária como uma mulher transexual. Conta, portanto, que desde 2008 "namorava" a ideia de ser travesti ou transexual, colocando as duas categorias como análogas (linhas 210 e 211). Apontamos que, ao trazer para a interação as identidades "travesti" e "transexual" como identidades análogas, pelas quais perpassa uma questão histórica, Rafaela realiza um movimento de resistência, negando discursos universalizantes que patologizam a transexualidade e fixam quesitos que devem ser preenchidos para que a pessoa seja reconhecida como uma/um "transexual verdadeira/o" (Borba, 2016). Contudo, logo em seguida, Rafaela justifica o uso do termo "travesti", destacando que na época não se usava, habitualmente, a categoria "transexual". Esse movimento demonstra que, embora Rafaela resista à compreensão da identidade transexual como uma identidade universal, ela entende que precisa adequar sua narrativa de maneira que sustente a (co)construção de um laudo que a ateste como transexual. Ademir sustenta a narrativa de Rafaela e dá sinais (linhas 213 e 215) para que ela siga com o relato. Rafaela conta, então, como o desejo de ser travesti/transexual the acompanhou desde a infância. Alega, contudo, que não pôde exercer essa vontade antes, pois sofreu pressão no trabalho para tomar "certa postura" (linha 229). Ademir toma o turno e questiona Rafaela sobre a necessidade de corresponder às pressões advindas de seu ambiente de trabalho. Podemos perceber que a resposta a essa pergunta já havia sido dada por Rafaela anteriormente (linhas 224 e 225), portanto, inferimos que a função desse questionamento não é obter uma resposta direta, mas estimular a narrativa de Rafaela sobre o ambiente hostil e transfóbico que é seu local de trabalho.

Temos outros indícios de que Ademir não busca uma resposta polar ( $\operatorname{sim} /$ não), pois os dois turnos produzidos por Rafaela que trazem respostas diretas (linhas 233 e 235) são sucedidos por períodos longos de silêncio (linhas 234 e 236), fazendo com que ela continue falando sobre o questionamento do psiquiatra. Nesse sentido, Ademir obtém êxito em sua intervenção, já que Rafaela passa a falar sobre seu ambiente de trabalho no momento presente (linha 237), o qual avalia como um cenário não "muito amistoso" por parte dos colegas de trabalho homens. Mais adiante, nessa mesma consulta, podemos ver a importância de investigar esse âmbito da vida de Rafaela, já que o ambiente de trabalho é, para ela, um dos locais de maior sofrimento no sentido de vivenciar situações de preconceito e transfobia (ver Excerto 2). Em seguida, Rafaela busca retomar algum tópico anterior da interação, entretanto afirma que se perdeu em sua narrativa (linha 248), convidando Ademir para tomar o turno. Ademir vem ao auxílio de Rafaela (linha 250) e engaja-se em produzir uma formulação dos turnos anteriores da cliente.

$\mathrm{Na} \mathrm{AC}$, o termo formulação refere-se à prática interacional de propor uma versão dos fatos que (aparentemente) surgem diretamente da fala anterior da/o interlocutora/ or. Podemos descrever, também, como enunciados em que a/o falante atual sugere um dos possíveis entendimentos do que foi dito em turnos anteriores pela/o interlocutora/ or (Heritage \& Watson, 1980). Nesse sentido, à medida que a interação prossegue, as/os participantes podem "formular" o que elas/es estão dizendo e oferecer seus entendimentos, interpretações ou representações do que suas/seus interlocutoras/es disseram anteriormente (Bercelli, Rossano, \& Viaro, 2008).

Embora Ademir faça uso de alguns termos não citados por Rafaela, podemos nomear essa prática interacional de formulação, pois o psiquiatra, embora transforme a forma do que foi dito, não modifica o sentido da fala da cliente. A formulação, nesse momento, 
é sequencialmente motivada, já que o terapeuta está respondendo ao turno de Rafaela, a qual pede ajuda para seguirem com a interação. Embora a prática de formular possa parecer carregar certa neutralidade, uma formulação é inevitavelmente seletiva: enfatiza algo na fala anterior e deixa outras coisas em segundo plano. Nesse caso, percebemos que Ademir traz como cerne da narrativa de Rafaela a sua construção como transexual, deixando de lado, por hora, as questões relacionadas à transfobia sofrida no ambiente de trabalho. Podemos entender que, nesse momento, a narrativa de Rafaela sobre sua construção identitária transexual está a serviço da tarefa institucional na qual terapeuta e cliente estão engajadas/os; portanto, essa narrativa (linhas 209 a 214 ) é selecionada por Ademir como o cerne dos turnos anteriores de Rafaela, e não as questões de sofrimento mais atuais (mesmo que esse tópico esteja sequencialmente mais próximo da formulação que se inicia na linha 250).

Observamos, também, que Ademir é muito cuidadoso para não fazer inferências contrárias à narrativa de Rafaela ao modular sua fala através de locuções como "de repente" e "parece que" (apontando que aquela é uma leitura possível da perspectiva expressa por Rafaela), além de, explicitamente, abrir espaço para que a cliente discorde de sua formulação ("me corrige se eu tô entendendo", linhas 256 e 257). Desse modo, Ademir está realizando uma prática característica das formulações: convida a interlocutora a confirmar ou desconfirmar a sua compreensão sobre aquilo que consiste, para ele, o cerne do que foi falado nos turnos anteriores. Ainda que a formulação possa acontecer em qualquer conversa cotidiana, quando dentro do setting terapêutico, ela pode estar a serviço da realização de tarefas institucionais, como por exemplo anamnese, diagnóstico, interpretação e a própria gestão interacional da sessão de terapia (Antaki, 2008). No excerto acima, a formulação parece estar a serviço de produzir uma narrativa inteligível dentro de um modelo de transexualidade, tornando, dessa maneira, possível a (co)construção de um laudo psiquiátrico que ateste a cliente como uma transexual verdadeira.

A formulação de Ademir (que se inicia na linha 259), no âmbito microinteracional, exerce a função de gerir o progresso interacional do atendimento, retomando a narrativa de Rafaela e colocando para avaliação a compreensão do terapeuta do que foi dito até ali. Nesse momento, Ademir não questiona o uso, por parte de Rafaela, dos termos "travesti" e "transexual" como identidades análogas. Ao não desafiar a asserção de Rafaela, Ademir parece alinhar-se com uma perspectiva que reconhece as identidades trans como construções identitárias singulares, exercendo, na interação, um papel político que difere da postura que é tomada por muitas/os profissionais que atendem a população trans. Notamos que a formulação do psiquiatra, ao não desafiar o movimento de resistência de Rafaela, produz um efeito importante na interação: se no início do excerto Rafaela produz uma série de hesitações através de fala alongada e repetições (linhas 209 e 210) antes de usar o termo travesti e, além disso, presta contas sobre o uso do termo (linhas 211, 212 e 214), ao final do excerto ela se demonstra muito mais assertiva e concorda prontamente (linhas 268 e 270) com a formulação de Ademir sobre sua identificação com a identidade travesti. A postura desse terapeuta difere da postura de profissionais da saúde mental observadas/os em outros estudos no Brasil, os quais analisaram a tentativa de estabelecer travestis e transexuais como construções identitárias distintas de maneira a materializar uma linguagem diagnosticamente apropriada para os objetivos do programa em que estão inseridas (Borba, 2014). 
A distinção entre travesti e transexual é algo que não perpassa os critérios diagnósticos referidos no DSM-5, manual que orienta o enquadramento ou não de determinado sujeito como uma/um "transexual verdadeira/o". Ademir parece compreender, portanto, que no caso de Rafaela, o uso do termo travesti é calcado em uma questão histórica típica do Brasil. Nesse sentido, Rafaela nomear-se como travesti (mesmo que como mera expressão de desejar tornar-se) não é encarado como um empecilho por Ademir. Portanto, fazer uso de maneira acrítica de um modelo diagnóstico como o DSM, no qual são trazidas concepções locais de gênero fortemente marcadas pelas características culturais de suas/ seus formuladoras/es, envolve não apenas a patologização da transexualidade, mas a própria imposição de um modelo metapragmático de identidade (Borba, 2016) que não reflete as vivências das pessoas que são enquadradas nesse modelo.

Torna-se pertinente citar que, em momento anterior não transcrito, Ademir presta contas para Rafaela afirmando que ele e o restante da equipe não concordam com a necessidade de um laudo para que ela tenha o direito de alterar seu nome e gênero. Dessa maneira, Ademir já havia demonstrado ter uma postura crítica em relação ao manual, ao diagnóstico de Transtorno da Identidade Sexual à própria patologização da transexualidade. A postura do terapeuta em relação ao laudo vai ao encontro do entendimento do próprio CFP, o qual vem desenvolvendo um trabalho árduo no âmbito da luta pela despatologização ${ }^{1}$. A necessidade de um laudo que ateste a identidade de gênero de um sujeito é controversa, pois enquanto não é exigido das pessoas cisgêneras nenhuma prova em relação à legitimidade quanto ao próprio corpo e gênero, as pessoas trans precisam a todo momento provar que há uma autenticidade em sua identidade de gênero (Conselho Federal de Psicologia [CFP], 2015). Portanto, as discussões em relação ao laudo psiquiátrico e psicológico devem confrontar a lógica na qual o sujeito, quando não se percebe dentro de um padrão em que existe uma linearidade entre marcadores biológicos e identidade de gênero, terá sua autonomia negada, em um processo que desqualifica qualquer experiência de gênero que não seja a cisnormativa (Vergueiro, 2015).

\section{Prestação de contas (Accountability)}

O Excerto 2 (Figura 2) se dá quando o atendimento já está se encaminhando para o final: neste momento, Ademir sugere à cliente que, na sua compreensão, ela teria indicação para iniciar psicoterapia. 


\section{Figura 2: Excerto 2}

\begin{tabular}{|c|c|c|}
\hline 1570 & Ademir & [ é: eu vou eu vou ] \\
\hline 1571 & & fazer o seguinte comentário (.) rafaela assim ó \\
\hline 1572 & & $(0,7)$ nós temos o entendimento que: (.) ã: (.) \\
\hline 1573 & & por exemplo gays lésbicas travesti transexuais \\
\hline 1574 & & $(0,5)$ não precisam fazer terapia por serem gays \\
\hline 1575 & & lésbicas transexuais ou [tra]vestis (.) entende \\
\hline 1576 & Rafaela & {$[$ sim $]$} \\
\hline 1577 & Ademir & não teria lógica essa indicação \\
\hline 1578 & & $(0,6)$ \\
\hline 1579 & Ademir & a indicação das pessoas fazerem psicoterapia é \\
\hline 1580 & & quando a gente percebe: $(0,3)$ que pode ter alguma \\
\hline 1581 & & coisa de conflito emocional que po[ssa] tá \\
\hline 1582 & Rafaela & [sim $]$ \\
\hline 1583 & Ademir & atrapalhando a pessoa (.) né $(0,3)$ e no teu caso \\
\hline 1584 & & eu diria (.) eu(.) como profissional da saúde \\
\hline 1585 & & mental diria que tu tem indicação de fazer \\
\hline 1586 & & psicoterapia (.) não pela questão (.) da da tua \\
\hline 1587 & & questão de de gênero [né por e]ssas conflitivas \\
\hline 1588 & Rafaela & [sim pelas $]$ \\
\hline 1589 & Ademir & ainda mais que de repente o que que eu tô \\
\hline 1590 & & imaginando $(0,4)$ é tu (.) a questão da \\
\hline 1591 & & retificação do teu nome e tu poder então te \\
\hline 1592 & & assumir como rafaela e de repente pode chegar no \\
\hline 1593 & & trabalho como rafaela $(0,3)$ tu vai te que tá \\
\hline 1594 & & preparada emocionalmente também pra poder lidar \\
\hline 1595 & & com isso (.) a própria questão da academia \\
\hline 1596 & & coisas do dia a dia entende onde de repente uma \\
\hline 1597 & & (.) um processo terapêutico poderia te ajuda:r \\
\hline
\end{tabular}

O foco central de análise nesse excerto é a prestação de contas. Percebemos que, antes de sugerir, de fato, o engajamento em um processo terapêutico, Ademir empenha-se em justificar o porquê da indicação. Em nossos dados, a prestação de contas (accountability) está presente em diversos momentos do atendimento e diz respeito a práticas interacionais em que uma/um atora/ator social constrói um enunciado para explicar um comportamento imprevisto ou inconveniente (Robinson, 2016). Aqui, refere-se à tentativa de Ademir de modificar, prospectivamente, a compreensão de Rafaela sobre sua indicação de psicoterapia.

Ademir demonstra que, em sua perspectiva, o fato de alguém não ser heterossexual ou não ser cisgênero não implica por si só a necessidade de psicoterapia (linhas 1570 até 1575), seguindo à risca as normativas do Conselho Federal de Psicologia (2018). A prestação de contas se dá nesse momento da interação devido à complexidade da relação entre transexualidade e as ciências psi no âmbito da despatologização das identidades trans, o que torna essa prática localmente relevante. Portanto, Ademir se antecipa à indicação de terapia e, antes de fazê-la, presta contas prospectivamente sobre tal ação, tornando claro que a indicação não é feita pelo fato de Rafaela ser transexual, mas por um "conflito emocional" (linha 1581) que possa atrapalhar a cliente. Finalmente Ademir afirma que, como profissional da saúde, pensa que Rafaela deveria engajar-se em um processo terapêutico (linha 1585).

A prestação de contas como prática recorrente durante a consulta parece envolver um dilema do próprio terapeuta: se por um lado Ademir não avalia como adequada a necessidade de um laudo para retificação do registro civil de Rafaela, por outro ele não consegue desvencilhar-se da tarefa de produzi-lo, já que a retificação via judicial demanda um laudo psiquiátrico. Além disso, a presença da transexualidade em um manual de transtornos mentais também demanda que Ademir se posicione como um profissional que não entende as identidades de gênero não-cisgêneras e não-heterossexuais como 
condições psicopatológicas. Desse modo, a prestação de contas surge como uma maneira de justificar as ações que virão a seguir na interação, sejam essas questionamentos em relação a experiências de vida de Rafaela ou a própria indicação de psicoterapia, como no Excerto 2.

Rafaela dá sinais de compreender o que é dito por Ademir (linhas 1576, 1582). Se inicialmente, durante a prestação de contas, Ademir fala sobre indicação terapêutica de maneira genérica, em determinado momento ele passa a falar da indicação de Rafaela de maneira específica (linha 1589). Nesse momento, ele resgata algumas questões trazidas pela cliente durante o atendimento, apontando situações que, atualmente, impedem Rafaela de viver sua transexualidade de maneira plena: o impedimento de frequentar a academia e a própria situação transfóbica vivenciada no ambiente de trabalho (como relatado por Rafaela no Excerto 1). A prestação de contas desempenha, assim, um papel importante nesse ponto da interação, já que Ademir deixa claro para Rafaela que o foco da terapia, se ela optar por seguir adiante, seriam seus conflitos emocionais, e não a transexualidade em si.

Embora Ademir construa interacionalmente uma postura livre de qualquer estigma e preconceito, ao final do atendimento ele acaba por reproduzir o mesmo caminho traçado por profissionais que têm como foco de trabalho a clínica: o psiquiatra dá ênfase ao sofrimento de Rafaela a partir de um viés individualista, perdendo de foco o fato de que o mundo normativo e os dispositivos que configuram a subjetividade do sujeito são geradores de sofrimento. $\mathrm{O}$ viés individualista de Ademir ressoa, por exemplo, quando esse faz uso do termo conflito emocional (linha 1581): essa expressão remete à ideia de um conflito interno de Rafaela, cabendo à cliente, portanto, resolver o problema psicoterapeuticamente e no âmbito privado. Outra ação que embasa essa asserção se dá no turno em que Ademir fala que um conflito emocional pode estar "atrapalhando a pessoa" (linha 1583). O entendimento de que situações de transfobia "atrapalham a pessoa" remete à ideia de que a função da psicologia é adaptar a pessoa a demandas sociais. Ou seja, a função da psicoterapia seria possibilitar que o sujeito não tenha conflitos diante dessas demandas sem questionar, entretanto, que demandas são essas. Apontamos que, embora Ademir traga um diferencial importante para a interação ao justificar suas ações, é necessária, também, uma postura reflexiva e ativa no sentido de questionar as normas que criam as situações de sofrimento relatadas pela cliente.

\section{Considerações finais}

$\mathrm{O}$ atendimento analisado ilustra duas práticas interacionais utilizadas em uma interação marcada pela tarefa institucional de (co)produção de um laudo psiquiátrico. Cada uma das práticas descritas desempenha uma função e permite que tanto terapeuta como cliente cumpram a tarefa subjacente. Percebemos que o terapeuta lança mão de formulações para tornar a narrativa da cliente uma narrativa inteligível dentro de um modelo de transexualidade proposto pelo DSM-5. Através de práticas interacionais, Ademir interpreta a fala de Rafaela a partir do manual, traduzindo a narrativa de maneira que se torne adequada e permita a produção de um laudo que possibilite a retificação de nome e gênero. Entretanto, esse não é um processo unilateral, pois a cliente precisa dar condições, a partir de sua narrativa, para que o laudo se sustente, sendo requisitado 
de Rafaela agentividade ao produzir a narrativa, mas também conformidade em relação às formulações de Ademir. A necessidade de um laudo psiquiátrico parece, portanto, limitar tanto cliente quanto terapeuta: Rafaela precisa "pagar um preço" sobre sua própria transexualidade, tendo que comprovar a autenticidade de sua identidade de gênero. $\mathrm{O}$ preço a ser pago é, no âmbito das ciências psi, a própria narrativa da cliente como uma experiência que se adeque ao que é hoje percebido como uma narrativa transexual legítima. O terapeuta, entretanto, também se vê refém de uma narrativa que dele é exigida, impelido a trabalhar a partir de uma matriz discursiva nosológica e a fazer uso de um manual diagnóstico que categoriza e descreve a experiência trans.

Se no âmbito micropolítico a melhor alternativa para Ademir é "fornecer" o laudo, porque assim entende que está possibilitando à cliente o acesso a determinado direito, podemos questionar quais críticas, reflexões e ações profissionais da saúde mental podem de fato realizar no âmbito macropolítico. A prestação de contas parece, assim, surgir como uma prática para atenuar a realização da tarefa de produção do laudo, com a qual Ademir afirma não concordar. O psiquiatra se coloca, portanto, como um terapeuta diferenciado e marca sua posição política através da prestação de contas: Ademir não apenas justifica a indicação de psicoterapia, deixando claro que não reconhece a transexualidade como um transtorno psiquiátrico, como também afirma que ele e a equipe não concordam com a necessidade de um laudo para retificação de nome e gênero. Essa prática surge como uma estratégia interacional, pois embora Ademir tenha sua autonomia limitada na condução da sessão, justifica para a cliente por que está conduzindo a entrevista daquela forma, permitindo assim que Rafaela se torne mais ativa e consciente do processo.

Desse modo, apontamos que o DSM-5 e a própria CID-11 são aparatos que, no âmbito do atendimento a pessoas trans, limitam a autonomia de ambos, cliente e terapeuta. Além disso, centram a problemática na pessoa, enquanto consolidam os dispositivos que mantêm a cisnormatividade como regra, gerando estigma e preconceito. Nessa perspectiva, o trabalho das ciências psi está em aberto: torna-se necessário tomar uma postura ativa, que afirme o papel de profissionais da saúde mental enquanto agentes de transformação e promotoras/es de saúde. Essa postura está de acordo com o que o CFP vem buscando realizar; entretanto, toda normativa é um conjunto de princípios que precisa ser transposto para a prática. É nesse sentido, pois, que se insere a importância de mais pesquisas que analisem a prática profissional nos seus detalhes, buscando fortalecer discursos que se alinhem à despatologização das transexualidades e travestilidades, demonstrando, de maneira empírica, como uma matriz discursiva nosológica está a serviço da manutenção de preconceitos, gerando sofrimento para pessoas que não se enquadram à cisheteronormatividade.

\section{Nota}

1 O engajamento do CFP se dá tanto a partir da publicação da resolução n. 1, de 29 de janeiro de 2018 (CFP, 2018), quanto da divulgação de publicações e vídeos veiculados em site produzido especificamente para o tema. Recuperado de https://despatologizacao. cfp.org.br/ 


\section{Referências}

Almeida, G. \& Murta, D. (2013). Reflexões sobre a possibilidade da despatologização da transexualidade e a necessidade da assistência integral à saúde de transexuais no Brasil. Sexualidad, Salud y Sociedad (Rio de Janeiro), 14, 380-407.

American Psychiatric Association - APA. (2013). Diagnostic and Statistical Manual of Mental disorders ( $5^{\text {thed. }}$.). Washington: Author.

Antaki, N. C. (2008). Formulations in Psychotherapy. In A. Peräkylä, C. Antaki, S. Vehviläinen, \& I. Leudar (Orgs.), Conversation Analysis and Psychotherapy (pp. 26-43). New York: Cambridge University Press.

Bagagli, B. P. (2016). A diferença trans no gênero para além da patologização. Revista Periódicus, 1(5), pp. 82-100.

Bento, B. (2016). Disforia de gênero: geopolítica de uma categoria psiquiátrica. Revista Direito e Práxis, 7(15), 496-536.

Bercelli, F., Rossano, F., \& Viaro, M. (2008). Clients' responses to therapists' reinterpretations. In A. Peräkylä, C. Antaki, S. Vehviläinen \& I. Leudar (Orgs.), Conversation Analysis and Psychotherapy (pp. 5-26). New York: Cambridge University Press.

Borba, R. (2014). (Des)aprendendo a "ser": trajetórias de socialização e performances narrativas no processo transexualizador. Tese de Doutorado, Programa Interdisciplinar de Pós-graduação em Linguística Aplicada, Universidade Federal do Rio de Janeiro, RJ.

Borba, R. (2016). Receita para se tornar um "transexual verdadeiro": discurso, interação e (des) identificação no processo transexualizador. Trabalhos em Linguística Aplicada, 55(1), 33-75.

Butler, J. (2015). Problemas de Gênero: Feminismo e Subversão da Identidade (8a ed.). Rio de Janeiro: Civilização Brasileira.

Carvalho, M. \& Carrara, S. (2013). Em direção a um futuro trans? Contribuições para a história do movimento de travestis e transexuais no Brasil. Sexualidad, Salud y Sociedad, 14, 319-351.

Conselho Federal de Psicologia - CFP. (2015). A despatologização das transexualidades e travestilidades pelo olhar da Psicologia: Parte I. [Arquivo de vídeo]. Recuperado de https:// www.youtube.com/watch? $\mathrm{v}=\mathrm{xLugxnORfd0 \& list=PLnzjy4Y6S0CNwQzRN4nazU13BWH-}$ -JQ1OH\&index $=2$

Conselho Federal de Psicologia - CFP. (2018). Estabelece normas de atuação para as psicólogas e os psicólogos em relação às pessoas transexuais e travestis. Recuperado em https://site. cfp.org.br/wp-content/uploads/2018/01/Resolução-CFP-01-2018.pdf

Conselho Nacional de Justiça - CNJ. (2018). Dispõe sobre a averbação da alteração do prenome e do gênero nos assentos de nascimento e casamento de pessoa transgênero no Registro Civil das Pessoas Naturais (RCPN). Recuperado em http://www.cnj.jus.br/busca-atos-adm?documento $=3503$

Garcez, P. M., Bulla, G. S., \& Loder, L. L. (2014). Práticas de pesquisa microetnográfica: geração, segmentação e transcrição de dados audiovisuais como procedimentos analíticos plenos. DELTA: Documentação de Estudos em Lingüistica Teórica e Aplicada, 30(2), 257-288.

Gomes De Jesus, J. (2012). Orientações sobre identidade de gênero: Conceitos e Termos. (1a ed.). Goiânia: Sertão, Núcleo de estudos e pesquisas em gênero e sexualidade/UFG. Recuperado de www.researchgate.net/publication/234079919 Orientacoes sobre Identidade de Genero Conceitos e Termos

Hepburn, A. \& Bolden, G. B. (2013). The Conversation Analytic Approach to Transcription. In J. Sidnell \& T. Stivers (Orgs.), The Handbook of Conversation Analysis (pp. 57-76). Oxford: Wiley-Blackwell. 
Heritage, C. \& Watson, D. R. (1980). Formulations as Conversational Objects. Semiotica, $3(4), 245-262$.

Loder, L. L. \& Jung, N. M. (2008). Fala-em-interação Social: Introdução à Análise da Conversa Etnometodológica. Campinas, SP: Mercado das Letras.

Peräkylä, A., Antaki, C., Vehviläinen, S., \& Lauder, I. (2008). Analysing psychotherapy in practice. In A. Peräkylä, C. Antaki, S. Vehviläinen \& I. Leudar (Orgs.), Conversation Analysis and Psychotherapy (pp. 5-26). New York: Cambridge University Press.

Robinson, J. (2016). Accountabiliy in social interaction. New York: Oxford University Press. Santos, M. F. L. (2011). A invenção do dispositivo da transexualidade: produções de verdade e experiências trans. Em Pauta, 9(28), 117-130.

Sell, M. \& Ostermann, A. C. (2015). A construção da significação da experiência do abuso sexual infantil através da narrativa: uma perspectiva interacional. DELTA: Documentação de Estudos em Lingüistica Teórica e Aplicada, 31(2), 307-332.

Silva, C. R., Andrade, D. N. P., \& Ostermann, A. C. (2009). Análise da conversa: uma breve introdução. ReVEL, 7(13), 1-21.

Speer, S. A. \& Parsons, C. (2006). Gatekeeping gender: Some features of the use of hypothetical questions in the psychiatric assessment of transsexual patients. Discourse \& Society, 17(6), 785-812.

Tavares, M. (2007). A entrevista clínica . In J. A. Cunha (Org.), Psicodiagnóstico V (pp. 4557). Porto Alegre: Artmed.

ten Have, P. (2012). Ethnomethodology and conversation analysis. In H. Cooper, P. M. Camic, D. L. Long, A. T. Panter, D. Rindskopf, \& K. J. Sher (Orgs.), APA handbook of research methods in psychology, Vol 2: Research designs: Quantitative, qualitative, neuropsychological, and biological (pp. 103-117). Washington: American Psychological Association.

Vergueiro, V. (2015). Por inflexões decoloniais de corpos e identidades de gênero inconformes: uma análise autoetnográfica da cisgeneridade como normatividade. Dissertação de Mestrado, Programa Multidisciplinar de Pós-graduação em Cultura e Sociedade, Universidade Federal da Bahia, Salvador, BA.

World Health Organization - WHO. (1992). ICD-10 International Statistical Classification of Diseases and Related Health Problems. Geneva: Author.

\section{MARCELA ALBERTI}

\section{https://orcid.org/0000-0002-1459-6445}

Mestra em Psicologia e Saúde pela Universidade Federal de Ciências da Saúde de Porto Alegre (UFCSPA).

Endereço: UFCSPA - Universidade Federal de Ciências da Saúde de Porto Alegre,

Departamento de Psicologia. Rua Sarmento Leite, 245, Prédio 1, Sala 207 -

Centro Histórico, Porto Alegre, RS, CEP: 90050-170.

E-mail: marcelaalberti343@gmail.com 


\section{WILLIAN MACIEL KRÜGER \\ https://orcid.org/0000-0001-7796-2556}

Bacharel em Psicologia pela Universidade Federal de Ciências da Saúde de Porto Alegre (UFCSPA).

E-mail: willian.mk83@gmail.com

\section{ALEXANDRE DO NASCIMENTO ALMEIDA \\ https://orcid.org/0000-0003-4485-9944}

Doutor em Letras (Linguística Aplicada) pela Universidade Federal do Rio Grande do Sul (UFRGS). Professor Associado do Departamento de Educação e Humanidades da Universidade Federal de Ciências da Saúde de Porto Alegre (UFCSPA). Professor do Programa de Pós-graduação em Ensino na Saúde (UFCSPA).

E-mail: alexandrea@ufcspa.edu.br

\section{LUCIA MARQUES STENZEL}

https://orcid.org/O000-0003-2040-1998

Doutora em Psicologia pela Pontifícia Universidade Católica do Rio Grande do Sul (PUCRS). Professora Associada do Departamento de Psicologia na Universidade Federal de Ciências da Saúde de Porto Alegre (UFCSPA). Professora do Programa de Pós-graduação em Psicologia e Saúde (UFCSPA).

E-mail: 1stenzel@,ufcspa.edu.br

\begin{tabular}{|c|c|}
\hline Histórico & $\begin{array}{l}\text { Submissão: 02/09/2019 } \\
\text { Revisão: 23/03/2020 } \\
\text { Aceite: } 27 / 05 / 2020\end{array}$ \\
\hline Contribuição dos autores & $\begin{array}{l}\text { Concepção: MA; WMK; ANA; LMS } \\
\text { Geração de dadlos: MA } \\
\text { Análise de dados: MA; WMK; ANA; LMS } \\
\text { Elaboração do manuscrito: MA; WMK; ANA; LMS } \\
\text { Revisões críticas de conteúdo intelectual importante: } \\
\text { MA; WMK; ANA; LMS } \\
\text { Aprovação final do manuscrito: MA; WMK; ANA; LMS }\end{array}$ \\
\hline $\begin{array}{l}\text { Consentimento de uso de } \\
\text { imagem }\end{array}$ & Não se aplica \\
\hline $\begin{array}{l}\text { Aprovação, ética e } \\
\text { consentimento }\end{array}$ & $\begin{array}{l}\text { O estudo foi aprovado pelo Comitê de Ética da Universidade } \\
\text { Federal de Ciências da Saúde de Porto Alegre (CEP/UFCSPA) }\end{array}$ \\
\hline Financiamento & Não houve financiamento \\
\hline
\end{tabular}


Anexo 1 - Sistema Jefferson de Transcrição

\begin{tabular}{|c|c|c|}
\hline Uso & Símbolo & Significado da Transcrição \\
\hline & ponto final & entonação descendente \\
\hline$?$ & ponto de interrogação & entonação ascendente \\
\hline , & Vírgula & entonação de continuidade \\
\hline palav- & hífen & marca de corte abrupto \\
\hline pala::vra & dois pontos & prolongamento do som (maior duração) \\
\hline palavra & sublinhado & sílaba ou palavra enfatizada \\
\hline PALAVRA & maiúsculas & intensidade maior ("volume alto") \\
\hline${ }^{\circ}$ palavra $^{\circ}$ & sinais de graus & intensidade menor ("volume baixo") \\
\hline$>$ palavra $<$ & sinais de maior do que e menor do que & fala acelerada \\
\hline$<$ palavra $>$ & sinais menor do que e maior do que & fala desacelerada \\
\hline hh & série de h’s & aspiração ou riso \\
\hline.$h$ & h's precedidos de ponto & inspiração audível \\
\hline$=$ & sinais de igual & elocuções contíguas, sem intervalo \\
\hline[] & Colchetes & início e fim de fala simultâneas/sobrepostas \\
\hline$(1,7)$ & números entre parênteses & $\begin{array}{l}\text { medida de silêncio } \\
\text { (em segundos e décimos de segundos) }\end{array}$ \\
\hline (.) & ponto entre parênteses & micropausa de até $2 / 10$ de segundo \\
\hline() & parênteses vazios & fala que não pode ser transcrita \\
\hline (palavra) & segmento de fala entre parênteses & transcrição duvidosa \\
\hline$(($ olha para baixo $))$ & parênteses duplos & descrição de atividade não-vocal \\
\hline
\end{tabular}

